\title{
Knowledge Transmission in Industrial Clusters: Evidence from EuroClusTex
}

\section{Ana Paula Lisboa Sohn, Filipa Dionísio Vieira, Nelson Casarotto Filho, Idaulo José Cunha \& Paula Regina Zarelli}

To cite this article: Ana Paula Lisboa Sohn, Filipa Dionísio Vieira, Nelson Casarotto Filho, Idaulo José Cunha \& Paula Regina Zarelli (2016) Knowledge Transmission in Industrial Clusters: Evidence from EuroClusTex, European Planning Studies, 24:3, 511-529, DOI: 10.1080/09654313.2015.1053845

To link to this article: https://doi.org/10.1080/09654313.2015.1053845

册 Published online: 23 Jun 2015.

Submit your article to this journal

III Article views: 213

Q View related articles ¿

View Crossmark data ¿

4 Citing articles: 1 View citing articles 진 


\title{
Knowledge Transmission in Industrial Clusters: Evidence from EuroClusTex
}

\author{
ANA PAULA LISBOA SOHN*, FILIPA DIONÍSIO VIEIRA**, \\ NELSON CASAROTTO FILHO*, IDAULO JOSÉ CUNHA* \& \\ PAULA REGINA ZARELLI*
}

*Department of Production Engineering, Federal University of Santa Catarina, Florianópolis, Brazil,
${ }^{* *}$ Department of Production and Systems, University of Minho, Guimarães, Portugal

(Received October 2014; accepted May 2015)

\begin{abstract}
Covering the knowledge economy scenario, this article attempts to illustrate the analysis of the employment of knowledge transmission channels in the EuroClusTex, cross-border textile and clothing cluster between northern Portugal and Galicia. Therefore, an exploratory research was conducted. Primary data were obtained through participation in events, from interviews with key informants (entrepreneurs, leaders of cluster support institutions and government representatives). The secondary data were provided by the cluster support institutions, international organizations and the literature review. The results showed that EuroClusTex contributes to the competitiveness of regions, boosting trade relations between Galicia and northern Portugal. The most effective knowledge transmission channels in EuroClusTex were identified as: imitation, relationship with suppliers, public policy and human resources training. Experiences similar to EuroClusTex can be considered and served as examples for the development of clustering policies in other countries.
\end{abstract}

Keywords: clusters; knowledge transmission; textile and clothing industry; geographic proximity

\section{Introduction}

The constant and accelerated changes imposed by the new competitive paradigm of the knowledge economy require from firms a capacity for innovation, which presupposes and requires the creation or acquisition of new knowledge. Thus, this research has as a main objective: the analysis of the employment of transmission channels in clusters; to do so, a thorough analysis of EuroClusTex was performed.

Correspondence Address: Ana Paula Lisboa Sohn, Department of Production Engineering, Federal University of Santa Catarina, Des. Pedro Silva, 2100, 801A_ZIP 88080-700, Florianópolis, Brazil. Email: anasohn@ hotmail.com

This article was originally published with errors. This version has been corrected. Please see Erratum (http://dx.doi.org/10.1080/09654313.2016.1143696) 
EuroClusTex is a cross-border cluster that intends fundamentally to consolidate an already existent reality, and is related to the bonding between textile and clothing firms in Galicia and in northern Portugal. With a top-down approach, the EuroClusTex project was promoted by ATP (Associação Têxtil e Vestuário de Portugal (Textile and Clothing Association of Portugal)), the CITEVE (Centro Tecnológico das Indústrias Têxtil e do Vestuário de Portugal (Technical Centre for Textiles and Clothing)), the Confederation of Industrial Textiles of Galicia (COINTEGA) and the AIPCLOP (Asociación de Industrias de Punto e Confección de Lugo, Ourense e Pontevedra), and supported by POCTEP-Cross-border Portugal-Spain. Essentially, the EuroClusTex project aims to increase cooperation and provide visibility for firms located in these regions. In northern Portugal, there is an underlined specialization in the production/manufacture of textiles and clothing, while Galicia has expertise in the creation of brands and distribution chains. Therefore, these regions are characterized as regions with distinct and complementary competencies. These characteristics united to the geographical proximity impulse an intense commercial exchange for many Galician firms, especially the Inditex (Zara) Group, subcontract manufacturing firms located in northern Portugal.

The main motivation for selecting this research topic about knowledge transmission channels is related to the characteristics of the knowledge economy. In this context, studies showing the importance of knowledge management in industrial clusters are increasing in number (Giuliani \& Bell, 2005; Maskell \& Malmberg, 2007; Kesidou \& Romijn, 2008; Morrison \& Rabellotti, 2009; Staber, 2009; Guo \& Guo, 2010, 2013; Ciravegna, 2011; Giuliani, 2011; Morrison et al., 2011; Zhang et al., 2011; Kesidou \& Snijdersb, 2012; Sohn et al., 2014). Authors Baptista and Swann (1998) state that the diffusion of knowledge is one of the main reasons to distinguish successful clusters from the other agglomerated specializations. In addition, since the first studies by Marshall, understanding knowledge-flow impacts on the generation of externalities emanating from joint action has been sought (Schmitz, 1999).

The formation of industrial clusters influences the way firms cooperate, share knowledge, organize and compete. In the literature, the role of knowledge transmission in clusters reflects intentional and formal mechanisms, leaving a research gap about how other informal and unintentional knowledge transmission mechanisms can influence knowledge flows. Inspired by that research gap, this study contributes to the understanding of a broad set of knowledge transmission channels in a cross-border and top-down cluster approach. It brings forward a framework for analysis of the employment of knowledge transmission channels.

There is still very little empirical evidence regarding a broad set of knowledge transmission channels, considering intentional and formal mechanisms, and informal and unintentional mechanisms. One of only a few exceptions is an empirical study by Guo and Guo (2010), which revealed, in the context of emerging countries, the importance of "knowledge spanning mechanisms". In this sense, more empirical research is needed to clarify the role of knowledge transmission, and the lack of studies related to top-down approaches and cross-border clusters is identified, considering that in recent years in Europe, crossborder cooperation in spatial planning has intensified. In this context, the research gap is related to analyse the intensity of a broad set of knowledge transmission channels in EuroClusTex.

This study also contributes to analysing the impact of geographic proximity on knowledge transmission in clusters. The importance of studies of geographic proximity has been 
widely stressed in the cluster literature (Torre \& Rallet, 2010). Yet, new insights from the inter-organizational network and cluster literature underline the role of non-local linkages in enabling firms in networks to enhance learning and to innovate.

This article is divided into five sections. In the introduction, the context of the investigation and the objective as well as its justification are presented. The second section is dedicated to exposing the theoretical fundamentals that guided the research. The third section describes the adopted methodology. The fourth presents research results. The present article concludes with the final considerations in the fifth section.

\section{Industrial Clusters: Knowledge Transmission Channels}

Research about industrial clusters has increasingly explored if and how clustering can be intentionally supported. Initiating clusters from top down is a central device of regional economic policy that produces cluster advantages for their members, such as increased exchange of information, new collaborations, better visibility and image of the industry group, and impulses on competitiveness and innovativeness (Fromhold-Eisebith \& Eisebith, 2005). It is pointed out that implicit top-down promotion is better suited to support immaterial qualities of socially embedded interaction, creates stronger motivation among cluster members and induces faster outcomes in terms of functional, innovationrelated collaboration affecting firm performance (Fromhold-Eisebith \& Eisebith, 2005).

The prospect of potential benefits from cluster initiatives for companies and regions encourages governments and other public sectors to launch cluster promotion policies. In general, public policies aim for regional development by increased productivity, faster innovation and new business formation (Aragon et al., 2014). Government policy can influence research, technology transfer and relationships among cluster firms (Guo \& Guo, 2010).

The knowledge perspective literature on industrial clusters can be categorized into two strands. One is the Marshallian perspective, and the other is localized knowledge spillovers (LKS). Marshall proposes the idea that the secrets of industry are "in the air" and available to firms located inside automatically. This view points to a transactionbased production system, and emphasizes the importance of spatial concentration (Guo \& Guo, 2010).

The LKS perspective points to learning-based knowledge systems in industrial clusters, and highlights that much of the interfirm exchanges occur outside clusters, which reveals that two types of knowledge exchange coexist: local and long-distance exchanges (Guo \& Guo, 2010). Furthermore, it has become clear that the geographical proximity between firms is not by itself the only way of facilitating knowledge exchange, and that the latter can also take place between distant partners, thanks in particular to the development of information and communication technologies (Baptista \& Swann, 1998; Torre, 2008). So, with LKS perspective, in this article it is believed that clusters are not presented as closed or isolated systems, but rather the contrary, as structures that pay special attention to relations with the outside, either through other actors or through national or supranational policies.

From LKS perspective, there are a broad range of studies about knowledge transmission channels inside clusters; through this, we can point to the research of Belderbos et al. (2013), Zeng et al. (2010), Kesidou and Romijn (2008) and others, that highlighted the importance of collaborative interaction with local customers, competitors and suppliers, 
in which learning-through-interacting is used to promote knowledge transmission. For example, the relationship between the companies that belong to the clusters and the foreign market (Giuliani \& Bell, 2005).

The cultural environment, related to the motivation for knowledge sharing between companies in the cluster, and to the predisposition to be open to knowledge from outside the cluster, has an influence on motivation to share and seek knowledge related to innovation (Britto, 2002; Vilana \& Monroy, 2010; Giuliani, 2011).

Another knowledge transmission channel is the process of recruitment of staff (employees) among companies inside and outside the cluster. The recruitment of staff has an impact on raising workforce productivity, and one reason for this could be tacit knowledge transmission (Belderbos et al., 2013). Training helps creation and dissemination of knowledge in clusters, and can be promoted by customers, own companies and technical training institutions (Zeng et al., 2010; Guo \& Guo, 2013).

Opportunities to develop collaborative partnership for innovation among companies and technical training institutions, universities and other companies located outside the cluster are important channels for knowledge creation and flow (Britto, 2002). Supporting cooperation projects increases the rate of innovation and technology transfer from research and development $(R \& D)$ institutions and universities and/or technical training institutions to industry. Within the scope of establishing innovation-supporting instruments, building networks between industry, $R \& D$ centres and academia plays a significant role and has a huge impact on the success of such activities (Guo \& Guo, 2010).

Imitation is an important knowledge transmission channel in industrial clusters. In this regard, Staber (2009) suggests that imitation without any close interaction can lead to learning in clusters, in particular, that concerning strategic business issues. Imitation configures itself as a traditional process of knowledge incorporation that originates incremental innovation of processes and products, adequate to peculiar occurrence cases where a raise in the offer is needed, in scenarios where product demand is not too great (Vieira \& Romero, 2009).

However, in order to cope with the new board of competition characterized by a new step in markets' globalization, which raises the competition level among firms associated with the raising of expectations of customers and clients, be it in faster preference changes or in terms of product sophistication, the success of clusters cannot be based on traditional learning processes.

The previous literature from the LKS perspective has ignored the potential complementary and/or substitution relationship among different knowledge transmission channels and pays a great deal of attention to intentional or formal mechanisms. Exceptions are Guo and Guo (2010) and Sohn et al. (2014). Guo and Guo (2010) argue that it is necessary to bring local and non-local, formal and informal, knowledge transfer and knowledge spillover, personal and impersonal, and vertical (between clients and suppliers) and horizontal (among rivals firms) knowledge transmission channels into research on knowledge networks in clusters.

\section{Methodology}

Regarding the adopted technical procedures and the employed method, the research is classified as a case study, supported by bibliographic and documentary research. The exploratory research has as its objective raising the familiarity of the researcher with 
the environment, fact or phenomenon, identifying the conditioning factors while answering to the questions "what?" and "why?" (Yin, 2003).

Selection of EuroClusTex as a case study meets the need to conduct research about innovative experiences of clustering in the current competitive paradigm imposed by the knowledge economy. EuroClusTex is a binational and top-down initiative between Portugal and Spain that is not configured as a natural cluster, due to its creation from the perception of valuable opportunities of combined action from the textile and clothing firms located in northern Portugal and Galicia, Spain.

EuroClusTex was created to promote the complementarities between two of the richest textile and clothing realities in Europe, to foster cooperation between its businesses and to increase the international projection of one of the most well-represented sectors. It is considered that this case is innovative for presenting the approximation of two realities geographically closely located in distinct countries, but with a high potential for cooperation and collaboration. The initiative is met, grounded in an important cooperation "capital" accumulated by the firms and economical agents from the neighbouring border regions. The project acts as a catalyst for this natural complementarity of these two sectorial realities, allowing the rise of flows of commercial and productive character while institutionalizing new cooperation modalities. The main objective of EuroClusTex is to promote a cross-border cluster that advocates contacts and cooperation practices among all the actors of the row located in northern Portugal and Galicia.

The "EuroClusTex" project unfolds itself in an objective series of more operational character related to: (a) supporting the organizational initiative; (b) boosting the creation of aggregated value and the increase of productive segments of excellence in the crossborder relation; (c) supporting the constitution of a network between the main entities of technological and scientific systems of the two regions with competencies in the sector and (d) promoting the international opening of the textile and clothing industry (TCI) to stimulate the creation of an image of excellence in the Euro region of northern Portugal-Galicia in one of its activity sectors with a higher international representativeness and projection. So, the reasons underlying the selection of EuroClusTex fall into: (a) the fact of being a bi-national and top-down approach constitutes remarkable singularity; (b) the economic importance of the TCI to the northern Portugal and Galicia regions for regional development of these two regions.

The research about knowledge transmission channels in EuroClusTex was carried out with primary and secondary sources. The secondary data were provided by the cluster support institutions, international organizations and the literature review that underpins the research. The primary data were obtained through interviews with 14 key subjects.

The definition of the sample was intentional, a population representative subgroup having been selected. With this course of action in the data collection, the selection of sources was prioritized that showed distinctive views from EuroClusTex, what lead to a selection of a broad range of respondents: employers, Ph.D. researchers, government members, and leaders of support entities of the textile industry and clothing industry in Portugal and in Galicia, Spain. Formal interviews were conducted with 14 key informants. The first interviews were conducted with leaders of associations responsible for the EuroClusTex project; the first respondent was the Director General of ATP, who is also Vice-President of the Association Selective Fashion \& Management Associative Intelligence Center Textile CENIT. These are followed by two interviews with the 
Director General of the COINTEGA, who is also the Director General of AIPCLOP, and the Director of the CITEVE, Portuguese institution of European reference for the promotion of innovation and technological development of textile and clothing, a private non-profit public service. The second part of the interviews was conducted with entrepreneurs who were elected with the help of ATP, COINTEGA, AIPCLOP and CITEVE. The selection of businessmen took into account the high influence of leader firms localized in EuroClusTex region. Despite the importance of government and industrial associations, the firm view is important to clarify the real impacts of EuroClusTex in promoting cooperation. We interviewed CEOs from the following companies: Somelos Group, LMA Alitecno, Tetribérica S.A, Tinamar and Monsardi-Gonzabell S.L. These companies can be categorized into different sizes but with at least 20 years of experience in the textile industry in Portugal and Galicia. It was considered necessary during the field research to interview researchers from local universities working with research in the TCI from northern Portugal and Galicia. So the sample was also composed of two Ph.D. professors of the School of Economics of the University of Minho in Portugal and the coordinator of the Escuela Superior de Diseño y Moda Goymar in Galicia. For an insight into the government perspective, two academics working in public institutions related to the industry development and innovation were selected. Then interviewed were the Secretary of State Advisor of Entrepreneurship, Competitiveness and Innovation at the Ministry of Economy and Employment of Portugal and a director of COTEC Portugal-Business Association for Innovation, an initiative of the President of Portugal with the support of the Prime Minister-and a group of companies established in Portugal.

The "I Foro Económico de la Moda", which occurred in La Coruña, Galicia, was a valuable opportunity for information collection about the configuration of EuroClusTex, and the strategic conduction of the TCI in Galicia and in northern Portugal. During the event, we had the opportunity to attend a lecture by the President of the Xunta of Galicia and to participate in discussions with entrepreneurs and Spanish and Portuguese experts. The event was promoted by the ATP, CITEVE and COINTEGA. It is underlined that all of these institutions supported the research.

The interviews had two stages. In the first stage, all of the interviewees were invited to talk about the following subjects: (a) the project EuroClusTex; (b) the advantages of participating in the cluster and (c) the changes in the competitive environment.

In the second stage, they analysed the frequency and intensity of use of the knowledge of the transmission channels in EuroClusTex. For this, a questionnaire was used that considered the existence of 10 categories of analysis related to 25 knowledge transmission channels inside clusters as presented in Table 1. For better understanding of the interviewed, a scale was adapted to measure the efficacy of the communication channels, considering level 1 as "not efficient" and level 7 as "very efficient". And, the intensity of usage of the knowledge transmission channels researched was unfolded in high (7-6), medium (5-3) or low (2-1). The use of 7-point Likert scale took into account an important aspect with regard to the limits of human ability to make distinctions, and the use of approximately seven response categories is the limit for the human ability to distinguish.

In order to verify this variation, the following were employed: (a) arithmetic mean, even without being recommended the application of arithmetic mean in the obtained results with the Likert scale in this research and (b) perception of the researchers, based on the 
Table 1. Simplified questionnaire

Categories of analysis and related studies Knowledge transmission channels

Relationship between firms (Britto, 2002; Guo - Degree of relationship between smaller \& Guo, 2010; Belderbos et al., 2013) companies to have a relationship with leading and innovative companies in the cluster

- Degree of relationship between companies to maintain relationships with innovative organizations outside the cluster

- Partnership actions for commercialization of products/services

- Partnerships for joint purchases between cluster companies

Relationship with the suppliers (Lundvall, 2009; Guo \& Guo, 2010)

- Influence of raw material suppliers in the innovation processes of companies in the cluster

- Influence of equipment suppliers in the innovation processes of companies in the cluster

Relationship with the government (Zeng et al.,

- Influence of public policies to encourage 2010) research and technology transfer between companies in the cluster

- Influence of public policies to promote the relationship between the companies in the cluster and the foreign market

Cultural environment (Britto, 2002; Giuliani, 2007, 2011; Guo \& Guo, 2010; Vilana \& Monroy, 2010)

- Motivation for knowledge sharing between companies in the cluster

- Management culture to be open to knowledge from outside the cluster

R\&D (Britto, 2002; Guo \& Guo, 2010; Zeng et al., 2010)

Human resources' recruiting (Guo \& Guo, 2010; Belderbos et al., 2013)

Human resources' formation (Britto, 2002; Guo \& Guo, 2010; Zeng et al., 2010)

- Presence of R\&D departments in the cluster companies

- Development of new technologies in R\&D departments of cluster companies

- Recruitment of staff (employees) among companies in the cluster

- Recruiting staff (employees) outside the cluster

- Frequency with which customers to promote training for companies in the cluster

- Frequency with which companies to promote technical training for their employees

- Frequency with which institutions such as CITEVE to promote the training of personnel of companies in the cluster

Collaborative development (Britto, 2002)

- R\&D activities among cluster companies and universities

- $\mathrm{R} \& \mathrm{D}$ activities among companies and technical training institutions

- R\&D activities among cluster companies

- $\mathrm{R} \& \mathrm{D}$ activities among companies in the cluster and the companies located outside the cluster

Imitation of processes and products from the competition (Guo \& Guo, 2010; Zeng et al., 2010)

- Imitation of best practices among companies in the cluster

- Imitation of the best practices of companies located outside the cluster 
Table 1. Continued

\begin{tabular}{ll}
\hline Categories of analysis and related studies & \multicolumn{1}{c}{ Knowledge transmission channels } \\
\hline Coded knowledge (Britto, 2002; Guo \& Guo, & $\begin{array}{l}\text { Influence of patents and licensing in innovation } \\
\text { 2010; Zeng } \text { et al., 2010) }\end{array}$ \\
$\begin{array}{ll}\text { processes of companies in the cluster } \\
\text { Impact of technical and academic publications } \\
\text { on innovations in products and processes of } \\
\text { cluster companies }\end{array}$ \\
\hline
\end{tabular}

Source: Elaborated by the authors.

discourse analysis through the interviews, interfered in determining the score attributed. Finally, it is highlighted that all interviews were recorded and the commentary made by the researched enhanced the results analysis.

\section{Results}

The presentation of the results covers the description of the TCI's general panorama in the two regions that compose EuroClusTex and the research results regarding knowledge transmission channels in the cluster.

\subsection{The TCI of Northern Portugal and of Galicia in Spain}

The Portuguese TCI is concentrated in the northern region of the country. Consisting of approximately three thousand firms with 180 thousand employees, it represents $12 \%$ of the total exportation of Portugal, 25\% of the employment and $10 \%$ of the transformation industry production. In terms of European Union, the Portuguese TCI represented $4 \%$ in production and in the business volume generated by the European TCI, which is composed of 27 member countries. In Europe, only Italy, France, Germany, Spain, the UK and Belgium are ahead of Portugal (Investineu, 2013).

Traditionally aimed internationally, the Portuguese TCI exported, in the year 2007, more than $67 \%$ of its production, representing more than $3 \%$ of the total exportation of the European Union. It also generated a surplus of 971 million euros, and was one of the national industries that contributed positively to the Portuguese balance of trade.

During the critical phase of the global economic crisis of 2008, textile and clothing production suffered a fall of $6.5 \%$ (Investineu, 2013). The effects of the crisis, and the cheap and qualified workforce offered in Asia forced changes in the competition patterns that were not being incorporated by most of the firms. A fall of trust in the public institutions was noted, due to the inertia faced with the changes in the competitive paradigm.

It was observed that some firms in the cluster reacted to economic challenges of the knowledge economy when facing the addition of value of products and services and the integration in the production chain. In this context, it can be seen that among the main forces of the Portuguese TCI the following are highlighted: tradition and know-how; culture and business to business relations; the employment of modern equipment and technologies; the advantages of the geographical and cultural proximity to the high scale consume market; the flexibility and reactivity (rapid response capacity); the existence 
of a complete row, dynamic and structured, supported by consistent competencies centres; the progressive arising of success cases of leader firms to the level of brands, distribution, logistics, both nationally and internationally; and the recognized quality of national products.

While northern Portugal has a long tradition of textile and clothing production, Galicia's industry began at the end of the twentieth century. Galicia is a small region within Spain; yet it consists of the most number of apparel companies per capita in the country. This makes the Galician market highly competitive. The presence of Inditex as a world champion of the cluster, the entrepreneurial tradition and the export orientation of Galicians have allowed the cluster to develop in the past and will be a crucial strength going forward (Bozdemir et al., 2009).

There is a high level of rivalry or competition within the cluster, with many players competing (over 700 companies) with each other and also with foreign competitors. The recent history of the apparel cluster in Galicia has had three distinct phases: (1) During the 1960s and early 1970s the demand for apparel was unsophisticated, demanding cheap and functional products. Also, due to the increased mechanization in the food processing industry, many women in this industry switched to textiles and apparel, increasing the supply of cheap available sewing ladies. The entrepreneurial drive started to appear in the cluster with the founding of small workshops that produced apparel. (2) In the 1980s and 1990s, Inditex, founded by emblematic Galician entrepreneur Amancio Ortega, revolutionized the industry with the fast-fashion concept, flooding the market with stylish and trendy yet affordable products (Bonnin, 2002). This internationally successful company allowed "Galician fashion" to take off, increasing the Apparel Cluster in Galicia. This period saw the consolidation not only of Inditex but of other brands and designers such as Adolfo Domínguez that brought characteristic trendy designs. (3) In early 2000s, Spain liberalized trade, allowing the entry of Chinese products. This increased product competition and started a trend among companies to relocate manufacturing facilities to emerging countries to take advantage of cheaper labour conditions. For example, from minimal in early 1990s, Inditex's sourcing from Asia was 22\% in 2002 and $34 \%$ in 2006 (Bozdemir et al., 2009).

Pellizari et al. (2011) suggested that among the main forces of the Galician TCI are highlighted: production expertise and know-how, service and product quality, complete structured value chain, product portfolio diversity (Fashion, technical, home-textiles, etc.), exporting profile. In the view of the authors, the main weaknesses of the TCI are situated in Galicia: weak organizational standards, small size of the domestic market, dependency of smaller firms on Inditex Group and a lack of horizontal cooperation culture.

Together, the northern Portugal and Galicia regions account for a surface of $50.852 \mathrm{~km}^{2}$ and a population of approximately 6.5 million inhabitants. Both regions' aggregated GDP sums up to 88.3 thousand million Euros (2005 figures), representing $8.3 \%$ of the total Iberian Peninsula income. Regarding imports and exports of goods, both regions have been able to maintain a relatively stable performance within the Iberian Peninsula context, being responsible for approximately $11 \%$ of international trade, and the import/export balance is much more positive than the average Iberian performance (Pellizari et al., 2011).

In both regions, there is an underlined representation of small and micro firms. Northern Portugal and Galicia are strongly integrated in terms of commercial exchanges. In relation to the commercial exchanges between Portugal and Galicia, it is highlighted that the sub-region of La Coruna, be it in the exportation levels (being responsible for more 
Table 2. Complementarities factors in EuroClusTex

\begin{tabular}{ll}
\hline \multicolumn{2}{c}{ EuroClusTex } \\
\hline Advantages of north of Portugal & Advantages of Galicia \\
\hline $\begin{array}{l}\text { Productivity capacity } \\
\text { Quality of product }\end{array}$ & $\begin{array}{c}\text { Commercial experience } \\
\text { Distribution and internationalization } \\
\text { management of brands }\end{array}$ \\
& $\begin{array}{c}\text { Mutual recognition of competences } \\
\text { Historic trade relations } \\
\text { Geographic and cultural proximity }\end{array}$ \\
\hline
\end{tabular}

Source: Adapted from EuroClusTex (2013).

than $84 \%$ of the exportations of textiles and for more than $92 \%$ of the clothing) or the importation levels $(62 \%$ of the textile importation and more than $83 \%$ of clothing products), is the most important commercial partner of Portuguese TCI. The textile and clothing importation originating in Galicia represents $37.9 \%$ of the total of Portuguese importation of these sectors, which originate in Spain (EuroClusTex, 2013).

The importance of La Coruña for northern Portugal is directly related to the Inditex Group, one of the main fashion distributors of the world located in the region. The Inditex Group has more than 120,000 employees and manages 6500 points of sale with different positioning and insignias (Zara, Pull and Bear, Massimo Dutti, Bershka, Stradivarius, Oysho, Zara Home, Kiddy's Class). It operates as an outsourcing global grid of production and distribution of final products and operates on a global scale; in this context, the regional clusters of northern Portugal and Galicia are figured as outsourced agents of production.

It can be noted that the presence of the Group Inditex in Galicia demonstrates the commercial experience and competency present in this region, which, allied to the productivity capacity of Portugal, propelled the implementation of EuroClusTex. It was observed that in Portugal and in Galicia, the firms have been valuing design, marking, innovation, logistics, and distribution and internationalization management of brands.

To improve the description of the Portuguese and Spanish sub-regions, the principal aspects that have facilitated the EuroClusTex project are presented in Table 2, highlighting the advantages and complementarities between the regions.

In summary, it is pointed that EuroClusTex project is based on a region with one of the strongest traditions in the textile/fashion sector in Europe, and where this sector is best represented, the northern Portugal-Galicia Euroregion. It is an area rich in "complementarities", with its vast industrial and manufacturing experience, and clear commitment to innovation through technical textiles in northern Portugal and with great vigour in distribution, marketing and the creation of brands in Galicia.

\subsection{Knowledge Transmission Channels Analysis}

Presented in this topic are the results concerning the usage intensity of the knowledge transmission channels listed in the research model described in the methodology.

To better understand the horizontal flux of knowledge (among rival firms), the data presented in Table 3 show that the degree of relationship among the strata of firms of lower 
Table 3. Firm relationships

\begin{tabular}{lc}
\hline Knowledge transmission channel & Score \\
\hline $\begin{array}{l}\text { Relationship degree among lower innovation capacity firms and innovator leader firms of the } \\
\text { cluster }\end{array}$ & 3.00 \\
$\begin{array}{l}\text { Relationship degree among the firms that belong to the cluster and other innovator firms and } \\
\text { organizations located outside the cluster territory }\end{array}$ & 4.00 \\
$\begin{array}{l}\text { Partnership actions for the commercialization of products/services development of the firms } \\
\text { of the cluster }\end{array}$ & 4.00 \\
Partnership frequency for combined purchase of the firms of the cluster & 2.00 \\
\hline
\end{tabular}

Source: Elaborated by the authors.

innovation capacity and the leader and innovator firms in the cluster is lower than the degree of relationship among the firms that belong to the cluster and other innovator firms and organizations located outside the cluster territory. This result can be explained by the Inditex Group's presence in Galicia, which demonstrates that the geographical proximity factor is losing importance. Perceived were a lower incidence of partnerships for combined commercialization and purchase and a medium frequency of partnerships for products/services commercialization. Additionally, one of the interviewed entrepreneurs emphasized that partnerships between firms are inhibited by the lack of support of local associations.

The low incidence of partnerships' development for the combined commercialization and purchase can be resulting from the lack of policies that stimulate these practices. These results can also occur from the lack of perception from the interviewees as to the importance of organizational missions and of events such as the "I Foro Económico de la Moda", promoted by the organizational associations that attend to the clusters in northern Portugal and Galicia. It can be observed that the organizations regularly offer opportunities for knowledge exchange amidst the entrepreneurs, universities and technological centres. The interviews exposed that these opportunities are not faced as partnership possibilities for combined sales or contact networks' expansion and knowledge exchange, and as such are being underused by the entrepreneurs.

To clarify the vertical knowledge flux (between clients and suppliers), the results presented in Table 4 show that in EuroClusTex there is medium and almost identical importance of relationships with equipment and machinery suppliers, and the raw matter suppliers.

It can be understood that, for the textile and clothing enterprises, the construction of good relations with the suppliers is considered a strategic factor since the suppliers bring valuable information of new technologies. In this way, these interactions can be

Table 4. Relationships with the suppliers

\begin{tabular}{lr}
\hline Knowledge transmission channel & Score \\
\hline $\begin{array}{l}\text { Influence of the raw material suppliers in the innovation processes of the firms of the cluster } \\
\text { Influence of the equipment/machinery suppliers in the innovation processes of the firms of } \\
\text { the cluster }\end{array}$ & 4.50 \\
\hline
\end{tabular}

Source: Elaborated by the authors. 
an opportunity for the creation of friendship and trust relationships that contribute towards knowledge transmission in an informal way.

In the EuroClusTex equipment, suppliers are located outside the clusters, in regions such as Italy, Germany and China, since the raw material suppliers are largely located inside the cluster.

According to Pellizari et al. (2011), one of the missing links of EuroClusTex is the absence of textile and clothing related machinery manufacturers. The author highlights that the geographical proximity between machinery manufacturers and textile companies very often results in mutual cooperation, leading to specific machinery adaptation which will allow a specific company to achieve a comparative advantage resulting from an almost "exclusive" development. We can note that this type of cooperation does not exist within the EuroClusTex region due to an absence of a strong textile and clothing machinery construction sector.

Also, the influence of the suppliers in EuroClusTex in knowledge transmission reveal that the firms of the cluster are in a distributed technology sector, and that innovation is not internally developed often, but rather, it is incorporated into productive processes with the purchase of machines, equipment and raw matter. The results covering the relationship with suppliers also reveal an influence loss of geographical proximity on the knowledge sharing in clusters.

Based on the exposed in Table 5, government influence is considered medium, but reveals the importance of a relationship with the government and stressed the importance of gatekeepers played by supporting organizations, such as ATP, CITEVE, COINTEGA and AIPCLOP.

It is highlighted that the public policies stimulate mechanisms which facilitate the transmission of internal and external knowledge. As an example, take the opportunity of the partnerships with international programmes, such as the Programa European Strategic Cluster Partnership (ESCP) that result in the participation of EuroClusTex in the Textile 2020. The Textile 2020 project promotes several official trips to the US, Canada, Brazil, Japan, South Korea, etc. With the aim of establishing important interclustering, business and technology partnerships, and providing opportunities to EuroClusTex members to keep in touch with external knowledge.

The interviewees revealed that the development of public policies does not take into consideration the market's necessities, what could lead to poor potential commercial opportunity taking. Another criticism that appeared throughout the research is that the public policies are focused on the increase of trust between firms in the two regions, and, however the proximity and interaction rhetoric between northern Portugal and Galicia take place in the discourse of politicians, it was noted that in order to stimulate

Table 5. Relationship with the government

\begin{tabular}{lr}
\hline Knowledge transmission channel & Score \\
\hline $\begin{array}{l}\text { Influence in the research and transference of technology activities among the firms of the } \\
\text { cluster }\end{array}$ & 4.00 \\
$\begin{array}{l}\text { Influence in the relationship promotion between the cluster's companies and the external } \\
\text { market }\end{array}$ & 4.00 \\
\hline
\end{tabular}

Source: Elaborated by the authors. 
Table 6. Cultural environment

\begin{tabular}{lr}
\hline Knowledge transmission channel & Score \\
\hline Motivation for knowledge sharing between the firms of the cluster & 3.30 \\
Firms' opening for knowledge acquisition outside the cluster & 4.30 \\
\hline
\end{tabular}

Source: Elaborated by the authors.

Table 7. Research and development

\begin{tabular}{lc}
\hline Knowledge transmission channel & Score \\
\hline R\&D departments in the firms of the cluster & 3.00 \\
Development of new technologies in the R\&D departments in the firms of the cluster & 3.00 \\
\hline
\end{tabular}

Source: Elaborated by the authors.

a more solid, efficient and effective collaboration it is required to implement initiatives that improve the trust bonds, that structure the communication and making of partnerships and business, avoiding duplication and overlapping of efforts.

In the cultural environment scope, the data presented in Table 6 show a wider opening for the acquisition of knowledge outside the cluster than for the motivation for sharing knowledge between the firms of the cluster. This result can be considered positive when related to the capacity of obtaining competitive advantages. However, it shows that geographical proximity loses importance with the advent of new ways of knowledge acquisition.

In the interviews, the entrepreneurs were observed to be more open to knowledge acquisition external to the cluster, for their activities are directed towards the global and the European market. It is observed that the changes in the competitive paradigm raised the competition and determined a reduction in the number of competitor firms located in the cluster.

According to the results presented in Table 7, the development of new technologies by the departments of R\&D of firms can be considered low. Nonetheless, it can be underlined that the firms from northern Portugal, which present a high cost in the workforce, and present a risk involved in innovation, especially those that act in the technical textiles market, seek to be distinguished through product innovation. This behaviour is reflected positively because data indicate that this market goes through a growth period.

In Galicia, most of the textile and clothing firms do not present R\&D departments, and innovation is aimed towards the creation and management of valuable brands, products commercialization and the supplies chain management. In this matter, the Inditex Group is cited as an example and the innovation related to the creation of what is labelled fast fashion.

As for the recruiting of human resources, the results presented in Table 8 show that it is medium and almost identical to the personal hiring inside the cluster compared to firms located outside it. This result can indicate that the location factor and the role of geographical proximity is not so important, considering that the firms do not carry many restrictions in amplifying the seeking of specialized workforce in other regions. 
Table 8. Human resources' recruiting

\begin{tabular}{lc}
\hline Knowledge transmission channel & Score \\
\hline Recruiting personnel among the firms of the cluster & 4.00 \\
Recruiting personnel from firms located outside the cluster & 3.50 \\
\hline
\end{tabular}

Source: Elaborated by the authors.

Table 9. Human resources' capacitation

\begin{tabular}{lc}
\hline Knowledge transmission channel & Score \\
\hline Formation promoted by clients for the firms of the cluster & 3.00 \\
Formation promoted by firms & 4.30 \\
Formation promoted by technical institutions & 4.50 \\
\hline
\end{tabular}

Source: Elaborated by the authors.

Table 10. Collaborative development

\begin{tabular}{lc}
\hline Knowledge transmission channel & Score \\
\hline $\begin{array}{l}\text { Frequency of occurrence of R\&D practices between the firms of the cluster and universities } \\
\text { Frequency of occurrence of R\&D practices between firms of the cluster and technical }\end{array}$ & 3.80 \\
$\quad$ formation institutions & 3.80 \\
$\begin{array}{l}\text { Frequency of occurrence of R\&D practices between firms of the cluster } \\
\text { Frequency of occurrence of R\&D practices between firms of the cluster and firms located } \\
\text { outside the cluster }\end{array}$ & 3.00 \\
\hline
\end{tabular}

Source: Elaborated by the authors.

It is also relevant to stress that the research identified that the TCIs go through a period of crisis and restructuring, and for these reasons, the hiring of personnel has been affected.

It can be noted how important the exchange of personnel among firms is, for they carry alongside the tacit knowledge, which is not available in books or manuals, and is considered as the main asset of firms.

Data from Table 9 reinforce that the capacitation promoted by clients is infrequent, while the capacitation promoted by firms and by knowledge centres, in special technical schools present a higher influence in the processes of knowledge transmission. The verification that the formation of human resources is configured as an important knowledge transmission channel inside EuroClusTex exposes dynamic competitive gains, which are associated to the advantages deriving from continuous enhancement.

The research reveals that in the European Union the firms are compelled by law to invest a profit percentage in the continued formation of its human resources. In this way, it is verified that the relatively high result of the human resources' formation importance made directly by the firms is resulting from public policies that interfere in the building of dynamic competitions for firms individually and for the cluster as a whole.

Data from Table 10 show that the frequency of activities that collaborate to R\&D between firms and universities, and between firms and technical formation institutions 
Table 11. Adoption of processes and products from the competitors-"imitation"

\begin{tabular}{lr} 
Knowledge transmission channel & Score \\
\hline Imitation degree of the best practices between firms of the cluster & 4.50 \\
Imitation degree of the best practices located outside the cluster & 4.50
\end{tabular}

Source: Elaborated by the authors.

is medium. The frequency of partnerships for R\&D between firms of the cluster is low; equally low is the practice of $R \& D$ activities between firms of the cluster located outside the cluster.

However, the existence of partnerships through the textile and clothing productive chain should be stressed. Thus, it is cited the example of a researched firm, specialized in the production of technical textiles, lacking the experience in selling clothing to attend the Inditex Group. For this reason, the firm formed a partnership with two other firms of the cluster, to develop the design and the confection of products and sell clothing to the Inditex Group, and another that executes the production of clothing. This example showed the potential of the partnerships promotion between the regional productive chains.

It was noted that the education entities and industrial associations of the region have a broader perception about the importance of achieving competitive advantages upon processes of knowledge exchange. However, it is verified that from the firms the importance of collaborative learning processes' recognition is non-existent.

Understanding the data presented in Table 11, it can be considered that imitation is the main transmission channel of knowledge in EuroClusTex. This result converges to what was exposed previously in Tables 6 and 7 because it considers that imitation practices inhibit motivation for the sharing of knowledge as well as the collaborative development processes between firms of the same sector.

It is considered that imitation is a practice of competitive advantage acquisition through copying and adaptation of product models that generate access to markets and is dependent on the capacity of creation and innovation of the leader firms (gatekeepers). In activities or industrial branches intensive in workforce with a big diversity in sizes in the role of the firm's cast, and with seasonal cycles of products as in the case of clothing firms, it can be stressed that imitation is transformed into a reactive strategy from small and medium firms.

With the result of the research, it can be observed that imitation, even though it is influenced by geographical proximity, is uniquely dependent on it. It was verified that the participation in business fairs, the workforce exchange and the ease of access to information on the internet, especially from fashion blogs, about tendencies and releases of big global labels stimulate imitation. It was verified also that the practice of imitation, as much as the influence of suppliers, is not dependent solely on geographical proximity.

Table 12 shows how low the influence of patents and licences in the process of knowledge transmission actually is. According to the data collected from the interviews, it can be perceived that the high incidence of imitation between firms is a factor that does not stimulate the acquisition of patents and licences. It is observed that technical and academic publishing have a low influence in the processes of innovation in the studied cluster. 
Table 12. Influence of coded knowledge

\begin{tabular}{lr}
\hline Knowledge transmission channel & Score \\
\hline Influence of patents and licences in the innovation processes in the firms of the cluster & 2.50 \\
Impact of technical and academic publishing in product and processes innovations in the & 3.70 \\
firms of the cluster &
\end{tabular}

Source: Elaborated by the authors.

The results showed the existence of a broad set of knowledge transmission channels inside the studied cluster, observing that the usage intensity and the impact on the products and processes innovation of these channels are varied. In the specific case of EuroClusTex, the most effective channels for knowledge transmission are: imitation between firms, relationship between firms and the suppliers, public policies and the formation of human resources.

\section{Conclusion}

There is no recipe for creating clusters or making innovation happen, but attempts to do so may have positive effects. In this sense, the present study differs from others (Capello, 2009; Morrison \& Rabellotti, 2009; Zeng et al., 2010; Ciravegna, 2011; Zhang et al., 2011; Huber, 2012; Kesidou \& Snijdersb, 2012; Gebreeyesus \& Mohnen, 2013) and contributes to the previous literature on knowledge within industrial clusters highlighting a broad set of knowledge transmission channels that influence innovation processes within industrial clusters.

Particularly in the case of EuroClusTex, a binational and top-down initiative, perhaps one important lesson is that they should be openly addressed in any formulation of regional or innovation policy. Reinforced is the fact of EuroClusTex being a cross-border cluster with highly important complementarities for two regions. It is highlighted that EuroClusTex promotes relations with the reinforcement of cooperation among several entrepreneurs, $R \& D$ institutions and associations of the textile and clothing sectors. The relationships established aim to qualify and intensify the innovative processes as a way to surpass the international concurrence promoted by countries where competitiveness is based on low-cost products, as well as to exchange experiences among the firms that operate in the sector. The results contribute to the correlation with previous studies of a wide range of knowledge of transmission channels (Guo \& Guo, 2013; Sohn et al., 2014) and others regarding clusters initiatives (Kowalski \& Marcinkowski, 2014) highlighting the influence of public policies that aim to promote the competitiveness which seeks to improve technology transfer.

The results presented showed that the knowledge transmission in EuroClusTex present different frequency of use and intensity. It was evident in the gatekeeper role played by supporting organizations. In this way, they stimulate the relation strengthening among firms, universities, research centres and technical schools. It is also crucial that policies, plans and strategies that stimulate the systematic acquisition of new knowledge are created.

Despite the importance of geographical proximity to create EuroClusTex, it was identified that the transmission of knowledge is not dependent only on geographical proximity. But, it also suffers influence from other factors such as culture and the adoption of appropriate public policies that stimulate collaboration. This statement in relation to geographic 
proximity shows itself evident in the results related to motivation for knowledge acquisition, recruiting of human resources, collaborative development and relationship with the suppliers and imitation. It is stressed that, geographic proximity does not guarantee the generation of trust between firms, nor the collaborative behaviour.

The analysis of the most used knowledge transmission channels in EuroClusTex, besides providing a base for future studies on this subject, contributes to the technicalscientific advance of researches about technological externalities in clusters.

In relation to the limits of the research, in the scope of interviews, it is stressed that most of the participants were from Portugal that could influence the generalization of results. Future research in EuroClusTex should involve a greater number of subjects, seeking a better balance between Galician and Portuguese participants. Considering its importance for the creation of EuroClusTex, the need to know the point of view of the Inditex Group is highlighted. In general, it is recommended that sample size should be increased for future work, as well as similar research be applied in other industries and clusters. This study may be enlarged and enhanced by a quantitative analysis, such as fuzzy Analytic Hierarchy Process, to help finding a set of important characteristics that allow plausibility for generalizations.

Finally, the analysis of the process of knowledge transfer may be extended to other clusters of other continents, in order to compare the different realities and try to help the development of clusters' policies to promote the innovation and the regional competitiveness. In this sense, it is stressed at last that the presented results take part in an international research regarding competition in clusters developed in Europe, Asia and South America.

\section{Acknowledgements}

The authors acknowledge the reviewers for their constructive comments.

\section{Disclosure Statement}

No potential conflict of interest was reported by the authors.

\section{Funding}

This work was financially supported by the Coordenação de Aperfeiçoamento de Pessoal de Nível Superior (CAPES) (National Council for the Improvement of Higher Education).

\section{References}

Aragon, C., Aranguren, M. J. \& Diez, M. A. (2014) Participatory evaluation: A useful tool for contextualising cluster policy? Policy Studies, 35(1), pp. 1-21. doi:10.1080/01442872.2013.803532

Baptista, R. E. \& Swann, P. (1998) Do firms in clusters innovate more?, Research Policy, 27(5), pp. 525-540. doi:10.1016/S0048-7333(98)00065-1

Belderbos, R., Van Roy, V. \& Duvivier, F. (2013) International and domestic technology transfers and productivity growth: Firm level evidence, Industrial and Corporate Change, 22, pp. 1-32. doi:10.1093/icc/ dts012

Bonnin, A. (2002) The fashion industry in Galicia: Understanding the 'Zara' phenomenon, European Planning Studies, 10(4), pp. 519-527

Bozdemir, G., Oliva, J. C., Jerez, P. \& Tamayo, E. L. (2009) Microeconomics of Competitiveness Apparel Cluster in Galicia-Spain (Boston, MA: Harvard Business School). 


\section{A.P.L. Sohn et al.}

Britto, J. (2002) Cooperação interindustrial e redes de empresas, in: D. Kupfer \& L. Hasenclever (Eds) Economia industrial: fundamentos teóricos e práticas no Brasil, pp. 345-388 (Rio de Janeiro: Campus).

Capello, R. (2009) Spatial spillovers and regional growth: A cognitive approach, European Planning Studies, 17(5), pp. 639-658. doi:10.1080/09654310902778045

Ciravegna, L. (2011) FDI, social ties and technological learning in new Silicon Valley clones. Evidence from the Costa Rican ICT cluster, Journal of Development Studies, 47(8), pp. 1178-1198. doi:10.1080/00220388. 2010.547935

EuroClusTex. Análise da Indústria Têxtil e Vestuário no Norte de Portugal e Galiza. Portuguese. Available at http://www.euroclustexplus.com/ (accessed May 2013).

Fromhold-Eisebith, M. \& Eisebith, G. (2005) How to institutionalize innovative clusters? Comparing explicit topdown and implicit bottom-up approaches, Research Policy, 34, pp. 1250-1268. doi:10.1016/j.respol.2005. 02.008

Gebreeyesus, M. \& Mohnen, P. (2013) Innovation performance and embeddedness in networks: Evidence from the Ethiopian footwear cluster, World Development, 41, pp. 302-316. doi:10.1016/j.worlddev.2012.05.029

Giuliani, E. (2007) The selective nature of knowledge networks in clusters: Evidence from the wine industry, Journal of Economic Geography, 7(2), pp. 139-168. doi:10.1093/jeg/lbl014F

Giuliani, E. (2011) Role of technological gatekeepers in the growth of industrial clusters: Evidence from Chile, Regional Studies, 45(10), pp. 1329-1348. doi:10.1080/00343404.2011.619973

Giuliani, E. \& Bell, M. (2005) The micro-determinants of meso-level learning and innovation: Evidence from a Chilean wine cluster, Research Policy, 34(1), pp. 47-68. doi:10.1016/j.respol.2004.10.008

Guo, B. \& Guo, J. J. (2010) Patterns of technological learning within the knowledge systems of industrial clusters in emerging economies: Evidence from China, Technovation, 31(2-3), pp. 87-104. doi:10.1016/j. technovation.2010.10.006

Guo, J. \& Guo, B. (2013) How do innovation intermediaries facilitate knowledge spillovers within industrial clusters? A knowledge-processing perspective, Asian Journal of Technology Innovation, 21(2), pp. 31-49. Special Issue: The roles of intermediaries in sectoral innovation systems and clusters in China and Thailand. doi:10.1080/19761597.2013.819245

Huber, F. (2012) Do clusters really matter for innovation practices in information technology? Questioning the significance of technological knowledge spillovers, Journal of Economic Geography, 12(1), pp. 107-126. doi:10.1093/jeg/lbq058

Investineu (2013) Textile Industry in European Union. Available at http://www.investineu.com/content/textileindustry-european-union (accessed 12 August 2013).

Kesidou, E. \& Romijn, H. (2008) Do local knowledge spillovers matter for development? An empirical study of Uruguay's software cluster, World Development, 36(10), pp. 2004-2028. doi:10.1016/j.worlddev.2008.01.003

Kesidou, E. \& Snijdersb, C. (2012) External knowledge and innovation performance in clusters: Empirical evidence from the Uruguay software cluster, Industry and Innovation, 19(5), pp. 437-457. doi:10.1080/ 13662716.2012 .711028

Kowalski, A. M. \& Marcinkowski, A. (2014) Clusters versus cluster initiatives, with focus on the ICT sector in Poland, European Planning Studies, 22(1), pp. 20-45. doi:10.1080/09654313.2012.731040

Lundvall, B.-A. (2009) The Danish model and the globalizing learning economy: Lessons for developing countries. Working papers UNU-WIDER research paper, World Institute for Development Economic Research (UNU-WIDER).

Maskell, P. \& Malmberg, A. (2007) Myopia, knowledge development and cluster evolution, Journal of Economic Geography, 7(5), pp. 603-18. doi:10.1093/jeg/lbm020

Morrison, A. \& Rabellotti, R. (2009) Knowledge and information networks in an Italian wine cluster, European Planning Studies, 17(7), pp. 983-1006. doi:10.1080/09654310902949265

Morrison, A., Rabellotti, R. \& Zirulia, F. L. (2011) When do global pipelines enhance knowledge diffusion in clusters? Evolutionary Economic Geography, Utrecht University.

Pellizari, F., Scheffer, M. \& Rosendo, H. (2011) In-depth Assessment of the Situation of the T\&C Sector in the EU and Prospects, European Commission Enterprise and Industry DG.

Schmitz, H. (1999) Collective efficiency and increasing return, Cambridge Journal of Economics, 23(4), pp. 465-483. doi:10.1093/cje/23.4.465

Sohn, A. L., Vieira, F. D., Casarotto, N. \& Cunha, I. J. (2014) Interorganizational learning: Study on the channels of knowledge transmission in textile and clothing clusters in Brazil and Portugal, Revista Alcance, 21(4), pp. 777-796. doi:10.14210/alcance.v21n4 
Staber, U. (2009) Collective learning in clusters: Mechanisms and bases, Entrepreneurship \& Regional Development, 21, pp. 553-573. doi:10.1080/08985620802529526

Torre, A. (2008) On the role played by temporary geographical proximity in knowledge transmission, Regional Studies, 42(6), pp. 869-889. doi:10.1080/00343400801922814

Torre, A. \& Rallet, A. (2010) Proximity and localization, Regional Studies, 39(1), pp. 47-59. doi:10.1080/ 0034340052000320842

Vieira, F. D. \& Romero, F. (2009) Network relations and innovative performance, in: International Conference on Technology Policy and Innovation, Porto, Portugal. Proceedings of the 12th International Conference on Technology Policy and Innovation, Porto, Portugal.

Vilana, J. R. \& Monroy, C. R. (2010) Influence of cultural mechanisms on horizontal inter-firm collaborations, Journal of Industrial Engineering and Management, 3(1), pp. 138-175. doi:10.3926/jiem.2010.v3n1.p138175

Yin, R. K. (2003) Applications of case study research, in: R. K. Yin (Ed.) Applied Social Research Methods Series, pp. 117-138 (London: Sage).

Zeng, S. X., Xie, X. M. \& TAM, C. M. (2010) Relationship between cooperation networks and innovation performance of SMEs, Technovation, 30, pp. 181-194. doi:10.1016/j.technovation.2009.08.003

Zhang, G., Xu, Q. \& Liu, X. (2011) Knowledge diffusion within the Datang sock-manufacturing cluster, China Regional Studies, 45(7), pp. 977-996. doi:10.1080/00343400802662641 